\title{
Vaccination Related Pain: Randomized Controlled Trial, Comparison of Pain of Two Injection Techniques
}

\author{
Mitesh Chawda ${ }^{1,}$, , Guruveerajeyasingh Malini ${ }^{2}$, Subodh Kumar Saha ${ }^{2}$, Shantilal Chawda ${ }^{3}$, \\ Ganpat Jha ${ }^{1}$, Ashish Wanare ${ }^{1}$, Ravi Prakash Pandey ${ }^{1}$, Hitav Someshwar ${ }^{4}$ \\ ${ }^{1}$ Resident Secondary DNB Pediatrics, Jawaharlal Nehru Hospital \& Research Center, Bhilai, Chhattisgarh, India \\ ${ }^{2}$ Department of Pediatrics, Jawaharlal Nehru Hospital \& Research Center, Bhilai, Chhattisgarh, India \\ ${ }^{3}$ Pediatrics, Rt. Chief Medical \& Health Officer, Govt. of Chhattisgarh, Korea, Chhattisgarh, India \\ ${ }^{4}$ Resident Neurophysiotherapy, K. J Somaiya College of Physiotherapy, Mumbai, Maharashtra, India
}

Email address:

drmitesh21@gmail.com (M. Chawda)

${ }^{*}$ Corresponding author

\section{To cite this article:}

Mitesh Chawda, Guruveerajeyasingh Malini, Subodh Kumar Saha, Ganpat Jha, Ashish Wanare, Ravi Prakash Pandey, Shantilal Chawda, Hitav Someshwar. Vaccination Related Pain: Randomized Controlled Trial, Comparison of Pain of Two Injection Techniques. American Journal of Pediatrics. Vol. 5, No. 3, 2019, pp. 133-141. doi: 10.11648/j.ajp.20190503.19

Received: May 8, 2019; Accepted: June 24, 2019; Published: August 6, 2019

\begin{abstract}
Background: Immunisations is one of commonest cause of iatrogenic pain among healthy infants though several authorities have recommended that no aspiration is required before injecting into the anterolateral thigh, it is still a commonly followed procedure. Method: 202 healthy infants of either sex of age group 6 weeks to 6 months receiving routine intramuscular pentavalent vaccine were selected randomly by computer generated numbers and divided into two groups "standard" group and "pragmatic" group with 101 infants in each group. Two methods of vaccination conventional and pragmatic are used. In both cases pre vaccination and post vaccination pain was accessed by using FLACC scale and modified behavioural pain scale as well as cry time was noted. Results: The pre vaccination mean FLACC score in standard group is $2.07( \pm 1.17)$ while that in pragmatic group is $1.79( \pm 1.28)$. Post vaccination mean FLACC score in standard group is 8.5 $( \pm 0.82)$ while that in pragmatic group is $7.79( \pm 1.25)$. The pre vaccination mean MBPS in both standard \& pragmatic group is $2.16( \pm 1.07)$. The post vaccination mean MBPS in standard group is 8.13 while that in pragmatic group is 8.16 . Conclusions: Our study revealed that there was significant difference in perception of pain among the two groups. The Pragmatic group being a better technique for vaccination.
\end{abstract}

Keywords: Vaccination Pain, Infant Vaccination, Different Technique

\section{Introduction}

An important responsibility of physicians who care for children is eliminating or assuaging pain and suffering when possible. It has been well documented, however, that in this regard a substantial percentage of children have been under treated [1]. The most common type of pain experienced by children is acute pain resulting from injury, illness, or in many cases necessary medical procedures. There is extensive literature that describes how to evaluate and treat acute pain in children using low-cost, widely available, convenient and safe methods, this information, however, has not been readily applied.
Barriers to the treatment of pain in children include the following [2].

1) The myth that children especially infants, do not feel pain the way adults do, or if they do there is no untoward consequence.

2) Lack of assessment and reassessment for the presence of pain.

3) Difficulty in conceptualizing and quantifying a subjective experience.

4) Lack of knowledge of pain treatment.

5) The notion that addressing pain in children takes too much time and effort.

6) Fear of adverse effects of analgesic medications, 
including respiratory depression and addiction.

Immunisations are among the most aversive medical procedures for healthy infants and children and one of the commonest cause of childhood iatrogenic pain [1, 3, 4]. Current recommendations of intramuscular vaccination are based almost exclusively on nursing experts opinion rather than randomized trials [5-11].

Though several authorities have recommended that no aspiration is required before injecting into the anterolateral thigh, it is still a commonly followed procedure. With the increasing number of vaccines available, the number of injections a child gets has correspondingly increased.

This study aims to identify whether the "pragmatic" method of injection is less painful than the conventional method, thereby decreasing the discomfort caused to the child and parents.

\section{Methodology}

This prospective randomized comparative study was conducted for a period of 1 year in an immunization OPD of a territory care hospital in chhattishgarg state of India. The study was conducted after seeking approval from Ethical Committee of the Institution. We recruited 202 healthy infants of both sex in the age group of 6 weeks to 6 months, they were receiving routine intramuscular pentavalent vaccine. The study sample size was calculated using the formula $\mathrm{n}=2(1.96+0.84)^{2} \mathrm{SD}^{2} / \mathrm{D}^{2}$ Assuming an $\alpha$ error of 0.05 and a $\beta$ error of 0.20 , the sample size calculated was minimum of 83 subjects in each group. Total 202 babies, 101 babies in each group i.e. "standard" group and "pragmatic" group were randomly taken by computer generated numbers to increase the power and reliability of study [41]. Consent was taken from the parents before including the babies in the study. Babies having chronic illness, any history of allergies to DTwP-Hib-Hep B or any of its components were excluded from the study. Babies having acute febrile illness or who required a topical anaesthetic for administering the vaccine were excluded from the study. The use of oral analgesics post vaccination (eg, paracetamol, ibuprofen) was not an exclusion factor and was recorded. A pre-designed, Pretested proforma was used as an outcome measure.

\subsection{Protocol}

The parents of infants visiting to immunisation out-patient department were approached and consent was taken. Study subject were selected as per above mentioned inclusion and exclusion criteria. After recruitment, details of babies were collected. Examination- vital signs, general physical examination, head to toe examination and other systems examined. Infants coming to immunization out-patient were selected by computer generated numbers and two methods of vaccination mentioned in study i.e. conventional and pragmatic method were used. In both cases pre vaccination and post vaccination pain was accessed by using FLACC scale and modified behavioural pain scale as well as cry time was noted and videos were recorded for record keeping.
Group A (Standard group): These infants received immunisation using standard slow technique.

Standard method is as follows (ANNEXURE IV)-

-Slow advancement of the needle into the muscle

-Slow aspiration prior to injection (the most important step, based on safety considerations, to ensure a blood vessel has not been penetrated)

-Slow injection time in order not to damage local tissue by the force of rapid injection (which may be painful)

-Slow withdrawal of needle after injection. Entire procedure was completed in 5-10 sec.

Group B (Pragmatic group): These infants received immunisation using "pragmatic" technique. (ANNEXURE IV)-

- Rapid advancement,

- No aspiration,

- Rapid injection and

- Rapid withdrawal of syringe.

Entire procedure was completed in 1-2 sec.

Only pentavalent conjugate vaccine supplied by the Govt under EPI (ANNEXURE V) was used for the study. $0.5 \mathrm{ml}$ of Vaccine was injected into the middle third of the anterolateral thigh after wiping with alcohol swab, using $2 \mathrm{ml}$ syringe with 24 gauge 1 inch needles. The muscle was compressed with the free hand during the injection procedure. Needles were inserted at an angle of $90^{\circ}$ in both techniques. Rubbing the immunization site after administration was avoided in both techniques. Small amount of bleeding at the injection site following vaccination was wiped gently with dry cotton. The immunisation procedure was standardised and was administered by a single person.

The entire vaccination procedure was videotaped using a colour digital camera beginning $5 \mathrm{sec}$ before the vaccine was administered and continuing for $1 \mathrm{~min}$ after the immunisation is completed \& infants were observed for 30 minutes post vaccination.

Videos were scored for pain using FLACC SCALE \& MBPS by 2 clinical psychologists who were unaware of the study objectives and infant group assignment. Scores were considered for statistical analysis. A baseline pain score $5 \mathrm{~s}$ prior to the vaccine injection and a post immunization pain score within $15 \mathrm{~s}$ of the immunization were measured and described the child's maximal pain response to the injection. Crying time was measured using the same videos by a different person. Cry time was measured from the start of cry till it ends. Each infant was followed-up on next day in OPD to look for any complications.

\subsection{Statistical Methods}

Data was compiled in Ms-excel and checked for its completeness and correctness. Then it was analyzed by using the SPSS for Windows (version 16.0) statistical software. Then data was presented in form of number and percentage. Qualitative data was analyzed using Chi-square test and $\mathrm{P}$ value $<0.05$ considered as a statistical significance. All means were expressed as mean \pm standard deviation. 


\section{Observation and Results}

A total of 202 infants were included in the study, which were randomized into standard group and pragmatic group of 101 infants each. Standard technique required a longer duration $(5-10 \mathrm{sec})$ when compared to pragmatic technique (1-2 sec). There were no significant differences between 2 groups for age, sex, weight, area of residence, gestational age and pentavalent vaccine dose number.

Table 1. Sex wise distribution of cases in both groups.

\begin{tabular}{lllll}
\hline \multirow{2}{*}{ Gender } & SG & \multicolumn{3}{l}{ PG } \\
\cline { 2 - 5 } & $\mathbf{N}$ & $\mathbf{\%}$ & $\mathbf{N}$ & $\mathbf{\%}$ \\
\hline Male & 60 & 59.41 & 55 & 54.46 \\
Female & 41 & 40.59 & 46 & 45.54 \\
Total & 101 & 100 & 101 & 100 \\
P value $=0.48$ & \multicolumn{4}{l}{ Not significant } \\
\hline
\end{tabular}

Table 1 shows the demographic details of our study group in relation to sex of infants. Amongst our 202 subjects for vaccination, 115 were male and 87 were female. In standard group there were $60(59.41 \%)$ male and $41(40.59 \%)$ females, while in pragmatic group $55(54.46 \%)$ males and 46 $(45.54 \%)$ females.

Table 2. Age wise distribution of cases in both groups.

\begin{tabular}{lllll}
\hline \multirow{2}{*}{ Age (months) } & SG & \multicolumn{3}{l}{ PG } \\
\cline { 2 - 5 } & $\mathbf{N}$ & $\mathbf{\%}$ & $\mathbf{N}$ & $\mathbf{\%}$ \\
\hline $1-2$ & 48 & 47.52 & 47 & 46.53 \\
$2-3$ & 21 & 20.79 & 17 & 16.83 \\
$3-5$ & 32 & 31.68 & 37 & 36.63 \\
Total & 101 & 100 & 101 & 100 \\
P value $=0.37$ & Not significant & & \\
\hline
\end{tabular}

Table 2 shows the demographic details of our study group in relation to age group. Amongst our 202 subjects for vaccination, 48 infants were between 1-2 months, 21 between 2-3 months and 32 between 3-5 months in standard group while in pragmatic group 47 infants were between 1-2 months 17 between 2-3 months and 37 between 3-5 months.

Table 3. Comparision of mean weight of cases in both groups.

\begin{tabular}{lll}
\hline Weight (Kg) & SG & PG \\
\hline Mean & 4.6 & 4.35 \\
SD & 2.99 & 1.01 \\
P value $=0.41$ & Not significant & \\
\hline
\end{tabular}

The table 3 suggests that the mean weight of infants was 4.6 in standard group while 4.35 in pragmatic group.

Table 4. Area of residence wise distribution of cases in both groups.

\begin{tabular}{lllllll}
\hline \multirow{2}{*}{ Residence } & SG & \multicolumn{3}{c}{ PG } & \multicolumn{3}{c}{ Total } \\
\cline { 2 - 7 } & N & \% & N & \% & N & \% \\
\hline Urban & 77 & 76.24 & 76 & 75.25 & 153 & 76.5 \\
Rural & 24 & 23.76 & 25 & 24.75 & 49 & 24.5 \\
Total & 101 & 100 & 101 & 100 & 202 & 100 \\
\hline
\end{tabular}

Table 4 shows distribution of cases according to their area of residence in which total of 153 cases were from urban population 77 in standard group and 76 in pragmatic group, while 49 from rural area, 24 in standard group and 49 in pragmatic group.

Table 5. Gestation wise distribution of infants in both groups.

\begin{tabular}{lllllll}
\hline \multirow{2}{*}{ Term } & SG & \multicolumn{3}{c}{ PG } & \multicolumn{3}{c}{ Total } \\
\cline { 2 - 7 } & N & \% & N & \% & N & \% \\
\hline Term & 91 & 90.1 & 93 & 92.08 & 184 & 91.08 \\
Preterm & 10 & 9.90 & 8 & 7.92 & 18 & 8.91 \\
Total & 101 & 100 & 101 & 100 & 202 & 100 \\
\hline
\end{tabular}

Table 5 shows that of the total 202 infants, 184 term and 18 were preterm. Also in standard group 91 (90.1\%) term while $10(9.9 \%)$ preterm infants were there. While in pragmatic group $93(92.08)$ term and 8 (7.92) preterm infants were there.

Table 6. Schedule wise distribution of cases in both groups.

\begin{tabular}{lllll}
\hline \multirow{2}{*}{ Pentavac dose } & SG & \multicolumn{3}{l}{ PG } \\
\cline { 2 - 5 } & N & \% & N & \% \\
\hline 1 & 51 & 50.5 & 49 & 48.51 \\
2 & 23 & 22.77 & 19 & 18.81 \\
3 & 27 & 26.73 & 33 & 32.67 \\
Total & 101 & 100 & 101 & 100 \\
P value $=0.31$ & Not significant & & \\
\hline
\end{tabular}

Table 6 shows that the total number of infants in standard group who received 1st dose of pentavalent vaccine were 51, 2nd dose were 23 and 3rd dose were 27 . While similarly number of infants in pragmatic group were 49, 19 and 33 who received 1 st 2 nd and 3 rd dose respectively.

Table 7. Comparision of mean cry time in infants of both group.

\begin{tabular}{lll}
\hline Cry time & SG & PG \\
\hline Mean & 37.39 & 31.18 \\
SD & 18.5 & 20.43 \\
P value $=0.024$ & Significant & \\
\hline
\end{tabular}

Table 7 shows difference in mean cry time in two groups. the pragmatic group having mean cry time significantly lower 31.18 with SD 18.5 compared to same in standard group 37.39 with SD 20.43.

Table 8. Comparision of mean pre vaccination flacc score in infants of both group.

\begin{tabular}{lll}
\hline FLACC score Pre vaccination & SG & PG \\
\hline Mean & 2.07 & 1.79 \\
SD & 1.17 & 1.28 \\
P value $=0.11$ & Not significant & \\
\hline
\end{tabular}

Table 8 suggests the difference in mean FLACC score among both groups before vaccination. The mean FLACC score in standard group is 2.07 while that in pragmatic group is 1.79 with SD of 1.17 and 1.28 respectively. 
Table 9. Comparision of mean post vaccination flacc score in infants of both group.

\begin{tabular}{lll}
\hline FLACC score Post vaccination & SG & PG \\
\hline Mean & 8.5 & 7.79 \\
SD & 0.82 & 1.25 \\
P value & $<0.0001$ HS & \\
\hline
\end{tabular}

Table 9 suggests the difference in mean FLACC score among both groups after vaccination. The mean FLACC score in standard group is 8.5 while in pragmatic group is 7.79 with $\mathrm{SD}$ of 0.82 and 1.25 in both groups respectively, which is significant unlike pre vaccination scores among both groups.

Table 10. Comparision of Pre Vaccination Mean Mbps Score in Both Groups.

\begin{tabular}{|c|c|c|c|}
\hline \multirow{2}{*}{ Prevac } & \multicolumn{2}{|c|}{ MBPS score } & \multirow{4}{*}{$P$ value $=0.83$ Not significant } \\
\hline & SG & PG & \\
\hline Mean & 2.16 & 2.16 & \\
\hline SD & 1.07 & 1.07 & \\
\hline
\end{tabular}

Table 10 suggests the difference in mean MBPS among both groups before vaccination. The mean MBPS in both standard \& pragmatic group is 2.16 with SD of 1.07 .

Table 11. Comparision of Post Vaccination Mean Mbps Score in Both Groups.

\begin{tabular}{|c|c|c|c|}
\hline \multirow{2}{*}{ Postvac } & \multicolumn{2}{|c|}{ MBPS score } & \multirow{4}{*}{$P$ value $=0.82$ Not significant } \\
\hline & SG & PG & \\
\hline Mean & 8.13 & 8.16 & \\
\hline SD & 0.96 & 0.91 & \\
\hline
\end{tabular}

Table 11 suggests the difference in mean MBPS among both groups after vaccination. The mean MBPS in standard group is 8.13 while that in pragmatic group is 8.16 with $\mathrm{SD}$ of 0.96 and 0.91 in both groups respectively.

Table 12. Comparision of Area of Residence Wise Difference in Mean Cry Time in Both Groups.

\begin{tabular}{llll}
\hline Cry time Mean \pm SD & SG & PG & P value \\
\hline Rural & $43 \pm 17.94$ & $30.12 \pm 21.26$ & 0.026 Significant \\
Urban & $35.64 \pm 18.44$ & $31.53 \pm 20.28$ & $0.19 \mathrm{NS}$ \\
\hline
\end{tabular}

Table 12 suggests that there was significant difference in mean cry time in infants belonging to rural area among both groups while there was no significant difference among both groups in infants residing in urban areas.

Table 13. Comparision of Area of Residence Wise Difference in Mean Flacc Score in Both Groups.

\begin{tabular}{llll}
\hline FLACC score Mean \pm SD & SG & PG & P value \\
\hline Rural & $8.63 \pm 0.65$ & $7.68 \pm 1.44$ & 0.005 Significant \\
Urban & $8.47 \pm 0.87$ & $7.83 \pm 1.19$ & 0.0002 Significant \\
\hline
\end{tabular}

Table 13 suggests that there was significant difference in mean FLACC score in both groups with respect to area of residence.
Table 14. Comparision of Area of Residence Wise Difference in Mean Mbps Score in Both Groups.

\begin{tabular}{llll}
\hline MBPS score Mean \pm SD & SG & PG & P value \\
\hline Rural & $8.17 \pm 0.96$ & $8 \pm 0.91$ & $0.53 \mathrm{NS}$ \\
Urban & $8.12 \pm 0.96$ & $8.21 \pm 0.91$ & $0.53 \mathrm{NS}$ \\
\hline
\end{tabular}

Table 14 suggests that there was no significant difference in mean MBPS in both groups with respect to area of residence.

Table 15. Comparision of Mean Cry Time in Term and Pre Term Infants in Both Groups.

\begin{tabular}{llll}
\hline Cry time Mean \pm SD & SG & PG & P value \\
\hline Term & $33.7 \pm 19.33$ & $38.12 \pm 17.21$ & $0.62 \mathrm{NS}$ \\
Preterm & $37.79 \pm 18.47$ & $30.58 \pm 20.65$ & $<0.01$ Significant \\
\hline
\end{tabular}

Table 15 suggests that there was significant difference in mean cry time among the two groups in preterm infants.

Table 16. Comparision of mean flacc score in term and pre term infants in both groups.

\begin{tabular}{llll}
\hline FLACC score Mean \pm SD & SG & PG & P value \\
\hline Term & $8.6 \pm 0.7$ & $8.6 \pm 0.74$ & $0.94 \mathrm{NS}$ \\
Preterm & $8.49 \pm 0.83$ & $7.72 \pm 1.26$ & $<0.001$ Significant \\
\hline
\end{tabular}

The table 16 suggests that there was significant difference in mean FLACC score both groups in preterm infants. While mean FLACC score in term infants was not significant among both groups.

Table 17. Comparision of mean mbps in term and pre term infants in both groups.

\begin{tabular}{llll}
\hline MBPS score Mean \pm SD & SG & PG & P value \\
\hline Term & $8.2 \pm 0.92$ & $8.6 \pm 0.72$ & $0.30 \mathrm{NS}$ \\
Preterm & $8.12 \pm 0.96$ & $8.11 \pm 0.92$ & $0.98 \mathrm{NS}$ \\
\hline
\end{tabular}

Table 17 suggests that there was no significant difference in mean MBPS in both groups with respect to gestational age.

Table 18. Immediate complications related to vaccine pain in both groups.

\begin{tabular}{lllllll}
\hline \multirow{2}{*}{ Complications } & SG & \multicolumn{3}{c}{ PG } & \multicolumn{3}{c}{ Total } \\
\cline { 2 - 7 } & N & \% & N & \% & N & \% \\
\hline Fever & 44 & 43.5 & 33 & 32.67 & 77 & 38.1 \\
Swelling & 25 & 24.75 & 16 & 15.84 & 41 & 20.29 \\
Redness and Swelling & 14 & 13.86 & 23 & 22.77 & 37 & 18.3 \\
Nil & 18 & 17.82 & 29 & 28.71 & 47 & 23.2 \\
Total & 101 & 100 & 101 & 100 & 202 & 100 \\
\hline
\end{tabular}

Table 18 suggests that most common complication on 2 nd day of vaccination was fever. Total 77 (38.1\%) infants suffered from mild to moderate degree of fever including both groups, 44 infants in standard group \& 33 infants in pragmatic group followed by swelling alone in $41(20.29 \%)$ infants, 25 in standard group and 16 in pragmatic group. While 37 (18.3\%) infants suffered with redness and swelling at local site with or without associated fever, 14 in SG \& 23 in PG. 
Table 19. Comparision of mean cry time in both groups according to schedule.

\begin{tabular}{llll}
\hline \multirow{2}{*}{ Pentavac dose } & \multicolumn{2}{l}{ Cry time $($ mean \pm SD) } & \multirow{2}{*}{ P value } \\
\cline { 2 - 4 } & SG & PG & \\
\hline 1 & $37.78 \pm 19.60$ & $33.24 \pm 20.90$ & $0.26 \mathrm{NS}$ \\
2 & $37.30 \pm 17.49$ & $28.89 \pm 21.16$ & $0.17 \mathrm{NS}$ \\
3 & $36.70 \pm 17.82$ & $29.42 \pm 19.59$ & $0.14 \mathrm{NS}$ \\
\hline
\end{tabular}

Table 19 suggests association between mean cry time with relation to dose of vaccination, there was no significant difference in mean cry time associated with the particular dose (1st 2nd or 3rd ) among the two groups.

Table 20. Comparision of mean flacc score in both groups according to schedule.

\begin{tabular}{llll}
\hline \multirow{2}{*}{ Pentavac dose } & \multicolumn{2}{l}{ FLACC $($ mean \pm SD) } & \multirow{2}{*}{ P value } \\
\cline { 2 - 4 } & SG & PG & \\
\hline 1 & $8.43 \pm 0.80$ & $7.79 \pm 1.25$ & 0.003 Significant \\
2 & $8.30 \pm 0.92$ & $7.57 \pm 1.53$ & $0.067 \mathrm{NS}$ \\
3 & $8.81 \pm 0.68$ & $7.9 \pm 1.07$ & $<0.0001$ Significant \\
\hline
\end{tabular}

Table 20 suggests association between mean FLACC score with relation to dose of vaccination, there was significant difference in mean FLACC score associated with the 1 st \& 3rd dose among the two groups.

Table 21. Comparision of mean mbps score in both groups according to dose.

\begin{tabular}{llll}
\hline \multirow{2}{*}{ Pentavac dose } & \multicolumn{2}{l}{ MBPS (mean \pm SD) } & \multirow{2}{*}{ P value } \\
\cline { 2 - 3 } & SG & PG & \\
\hline 1 & $8.13 \pm 0.94$ & $8.06 \pm 0.96$ & 0.69 \\
2 & $8.08 \pm 0.84$ & $8.05 \pm 1.02$ & 0.90 \\
3 & $8.14 \pm 1.09$ & $8.36 \pm 0.74$ & 0.37 \\
\hline
\end{tabular}

Table 21 suggests association between mean MBPS with relation to dose of vaccination, there was no significant difference MBPS associated with the particular dose (1st 2nd or 3rd) among the two groups.

Table 22. Comparision of gender wise difference of mean cry time in both groups.

\begin{tabular}{llll}
\hline \multirow{2}{*}{ Gender } & \multicolumn{2}{l}{ Cry time (mean \pm SD) } & \multirow{2}{*}{ P value } \\
\cline { 2 - 3 } & SG & PG & \\
\hline Male & $39.67 \pm 18.65$ & $31.89 \pm 20.57$ & 0.035 Significant \\
Female & $34.04 \pm 17.96$ & $31.32 \pm 20.44$ & $0.37 \mathrm{NS}$ \\
\hline
\end{tabular}

Table 22 demonstrates relation between mean cry time with relation to gender of infants. There was significant difference found in mean cry time in males among standard and pragmatic group. While no significant difference was found in females of the two groups.

Table 23. Comparision of gender wise difference of mean flacc score in both groups.

\begin{tabular}{llll}
\hline \multirow{2}{*}{ Gender } & \multicolumn{2}{l}{ FLACC $($ mean \pm SD $)$} & \multirow{2}{*}{ P value } \\
\cline { 2 - 3 } & SG & PG & \\
\hline Male & $8.56 \pm 0.87$ & $7.82 \pm 1.21$ & 0.0002 Significant \\
Female & $8.41 \pm 0.74$ & $7.76 \pm 1.30$ & 0.0058 Significant \\
\hline
\end{tabular}

Table 23 demonstrates relation between mean FLACC Score with relation to gender of infants. There was significant difference found in mean FLACC score in both males and females among standard and pragmatic group.

Table 24. Comparision of gender wise difference of mean mbps score in both groups.

\begin{tabular}{llll}
\hline \multirow{2}{*}{ Gender } & MBPS & \multirow{2}{*}{ P value } \\
\cline { 2 - 3 } & SG & PG & \\
\hline Male & $8.16 \pm 0.88$ & $8.09 \pm 0.92$ & $0.65 \mathrm{NS}$ \\
Female & $8.07 \pm 1.05$ & $8.24 \pm 0.90$ & $0.43 \mathrm{NS}$ \\
\hline
\end{tabular}

Table 24 demonstrates relation between mean MBPS with relation to gender of infants. There was no significant difference found in mean MBPS score associated with any particular gender (male or female) in standard or pragmatic group.

\section{Discussion}

In recent years, there have been studies done on how to modify and reduce pain associated with immunisation [4]. Most of the studies are on pharmacological and other ways of reducing pain prior to immunisation $[42,43]$ and post immunisation pain $[44,45]$ rather than addressing vaccine administration technique. The present study aimed at reducing the pain by modifying the vaccination technique.

Modifying vaccine injection technique, such as not aspirating and reducing aspiration speed in order to reduce acute pain is advantageous in many ways. It is easy to implement and requires less time. It is also cost effective compared with other methods of pain reduction such as pharmacological method. Other advantages of not aspirating include better parental vaccine compliance because of reduced pain and the administration of more injections at the same visit because of less overall injection time.

As there are differences in the physical nature of the vaccines (DTwP is more likely to cause pain compared with DTaP and Hep B), only pentavalent vaccine with wP component which was supplied by the government for national immunization program was used for the study.

\subsection{Demographage Profile}

During our study period of one year (June 2017 to May 2018), of the total neonates who were vaccinated in our vaccination OPD, 202 neonates getting vaccinated with pentavalent vaccine, were selected randomly according to computer generated numbers.

In our study the males outnumbered females, accounting for $115(56.90 \%)$ cases, while females were $87(43.33 \%)$ cases which is in accordance with the studies carried out by Taddio A1, Nulman I, Goldbach M [43], in which 48 were males $(50 \%)$ while 48 were females $(50 \%)$ and in study carried out by Girish G N, Mandyam Ravi [46] males were $127(63.5 \%)$ while females were $73(36.5 \%)$ whereas in study conducted by moshe Ipp et al total number of males were $58(51.33 \%)$ while females were $55(48.67 \%)$ [47]. The male to female ratio in our study was $1.74: 1$. This preponderance of males over females in our study could be 
due to social beliefs that male babies are cared better by their parents. A total of 202 infants, 101 in each group formed the sample size. In a similar study by Moshe Ipp et al done in 2007, [47] there were total 113 infants, 57 in standard and 56 in pragmatic group whereas a study conducted by Girish $G$ N, Mandyam Ravi et al [46] in 2014 there were 200 infants, 100 in each group.

In the present study, infants between the age group of 6 weeks to 6 months were included, in contrast to Moshe Ipp et al [47], where infants between 4-6months age group was considered, whereas by Girish G N, Mandyam Ravi et al [46] infant between 6 weeks to 18 months were included. The present study demonstrates that the standard technique using slow aspiration and slow intramuscular injection of pentavalent vaccine is significantly more acutely painful than a pragmatic rapid injection. Aspiration prior to intramuscular immunisation is a widespread clinical practice that has been implemented for decades [6, 9] yet has never been substantiated by scientific data. Though there are no major blood vessels in the recommended sites for vaccination [48] the previous guidelines were to aspirate before giving vaccine. This was recommended in order to avoid inadvertent injection of vaccine intravascularly instead of intramuscular. However, there have never been any reported complications following inadvertent intravascular injection into the anterolateral thigh or deltoid muscle during immunisation. The aspiration component of this recommended technique may also not accomplish the safety objective for which it was designed, because in practice most vaccinators are "pragmatic" and perform the procedure too quickly for it to be effective (and visualise a flash back of blood [49].

\subsection{Comparision of Mean Pain Score with Other Studies}

The primary objective of the present study was to compare the acute pain response during immunisation in the two groups. In the present study the mean post vaccination FLACC score in standard group was 8.5 while 7.79 in the pragmatic group and the difference between the groups was significant $(\mathrm{p}<0.0001)$. Although mean post vaccination MBPS is 8.13 in standard group and 8.16 in pragmatic group with no significant difference $(\mathrm{p}=0.82)$. Moshe et al also noticed significant difference in MBPS between the standard group (5.6) and pragmatic group (3.3), with a $\mathrm{p}$ value of $<0.001$ [47]. Girish G N et al also noticed, in a similar study, the difference in mean MBPS in two groups which was 8.4 in standard group while 7.8 in pragmatic group, and the difference between mean scores of two groups was significant (p 0.00) [46].

The increased pain following vaccination in the standard group may be due to the combined effects of prolonged exposure to the needle and tissue irritation from needle movement.

\subsection{Comparison of Cry Time with Other Study}

The secondary objective of the study was to assess the crying time of two groups. Crying duration in pragmatic group was less $(31.18 \mathrm{sec})$ than standard group $(37.39 \mathrm{sec})$, it was statistically significant (p 0.024). Moshe et al also found a significant difference in the crying duration between standard $(8.7$ - $35.6 \mathrm{sec})$ and pragmatic group $(0-11.3 \mathrm{sec})$ [47]. While in a similar study done by Girish et al Mean crying duration in pragmatic group was less (32.1 s) than standard group (37.37 s) but was not significan [46].

The above differences in the mean pain scores and crying time between the studies can be explained by the following facts:

1. Moshe Ipp et al have used DTaP-Hib vaccine for the study which has lesser irritant quality compared to the DTwPHep-B-Hib which is used in the present study.

2 . Pre vaccination analgesics were used for some the cases in Moshe's study.

3. In the present study, babies were put supine on bed and then vaccinated where as in Moshe's study babies were in mother's lap or carried by mother.

Previous studies have demonstrated that expert opinions regarding massage of the injection site, location of injection site, injection of an air bubble and changing the needle prior to injection were not substantiated when later subjected to scientific rigor $[45,50]$.

In the paediatric vaccination setting, the practice of aspirating during the administration of an intramuscular injection is unnecessary and there is no clinical reason to suggest that these principles may not be applied when using the deltoid, ventrogluteal and vastus lateralis sites in other settings. [51]

There were no immediate adverse events observed in any infant. Strengths of the present study are that

1. It was a randomised controlled design.

2. The use of 2 different evaluators to measure infant pain responses through video tape.

3. All 202 vaccinations were done by a single person.

The limitations of the present study were that

1. The study was limited to intramuscular immunisation only and is not necessarily generalisable to aspiration prior to other intramuscular injections such as medication administration.

2. It is difficult to ascertain the relative contribution of injection speed versus aspiration on the observed overall reduction in pain.

\section{Conclusion}

1) During our study period of one year (june 2017 to may 2018), A total of 202 infants were included in the study, which were randomized into standard group and pragmatic group of 101 infants each. Standard technique required a longer duration $(5-10 \mathrm{sec})$ when compared to pragmatic technique (1-2 sec).

2) Amongst our 202 subjects for vaccination, 115 were male and 87 were female. the male to female ratio was $1.3: 1$. In standard group there were $60(59.41 \%)$ male and $41(40.59 \%)$ females, while in pragmatic group $55(54.46 \%)$ males and $46(45.54 \%)$ females. There was no significant 
difference with respect to sex of infants in both groups.

3) Amongst our 202 subjects for vaccination, 48 infants were between 1-2 months, 21 were between 2-3 months and 32 were between 3-5 months in standard group while in pragmatic group 47 infants were between 1-2 months 17 were between 2-3 months and 37 were between 3-5 months. There was no significant difference with respect to age in both groups.

4) The mean weight of infants was 4.6 in standard group while 4.35 in pragmatic group. There was no significant difference in mean weight among the groups.

5) Of the total population in our study 153 cases belonged to urban population 77 in standard group and 76 in pragmatic group, while 49 were from rural area, 24 in standard group and 49 in pragmatic group having no significant difference.

6) In our study, of the total 202 infants, 184 were term and 18 were preterm. In standard group $91(90.1 \%)$ term while 10 $(9.9 \%)$ preterm infants, while in pragmatic group 93 (92.08) term and 8 (7.92) preterm infants were there. Showing gestation wise similar distribution in both groups.

7) Total number of infants in standard group who received $1^{\text {st }} 2^{\text {nd }}$ and 3 rd dose of pentavalent vaccine were 51, 23 and 27 respectively. While similarly number of infants in pragmatic group were 49,19 and 33 who received 1st 2nd and $3 \mathrm{rd}$ dose respectively. There were no significant differences between 2 groups for pentavalent vaccine dose number.

8) Mean cry time in the pragmatic group was 31.18 seconds with SD 18.5 as compared to 37.39 seconds with SD 20.43 in standard group, suggesting a significant difference in mean cry time among both groups.

9) The pre vaccination mean FLACC score in standard group is 2.07 while that in pragmatic group is 1.79 with SD of 1.17 and 1.28 in both groups respectively. The difference in mean FLACC score among both groups before vaccination was not significant.

10) Contrarily the post vaccination mean FLACC score in standard group is 8.5 while that in pragmatic group is 7.79 with SD of 0.82 and 1.25 in both groups respectively, which is significant unlike pre vaccination scores among both groups.

11) The pre vaccination mean MBPS in both standard \& pragmatic group is 2.16 with $\mathrm{SD}$ of 1.07. suggesting no significant difference in mean MBPS among both groups.

12) similarly The post vaccination mean MBPS in standard group is 8.13 while that in pragmatic group is 8.16 with SD of 0.96 and 0.91 in both groups respectively, showing no significant difference in mean MBPS among both groups.

13) There was significant difference in mean cry time in infants belonging to rural area among both groups while there was no significant difference among both groups in infants residing in urban areas. There was significant difference in mean FLACC score in infants belonging to rural as well as urban area among both groups. There was no significant difference in mean MBPS in both groups with respect to area of residence.

14) There was significant difference in mean cry time among the two groups in preterm infants. There was significant difference in mean FLACC score both groups in preterm infants. While mean FLACC score in term infants was not significant among both groups. There was no significant difference in mean MBPS in both groups with respect to gestational age.

15) The most common complication on 2 nd day of vaccination was fever. Total 77 (38.1\%) infants suffered from mild to moderate degree of fever, 44 infants in standard group \& 33 infants in pragmatic group followed by swelling in $41(20.29 \%)$ infants, 25 in standard group and 16 in pragmatic group. While $37(18.3 \%)$ infants suffered with redness and swelling at local site with or without associated fever.

16) When the mean cry time, mean FLACC score and mean MBPS with relation to schedule of vaccination was compared, there was no significant difference in mean cry time or MBPS associated with the particular dose (1st 2nd or 3rd) among the two groups, but there was significant difference in mean FLACC score associated with the 1st \& 3rd dose among the two groups.

17) Similarly relation between mean cry time, mean FLACC score and mean MBPS with relation to gender of infants shows that there was significant difference found in mean cry time in males among standard and pragmatic group. While no significant difference was found in females of the two groups while there was significant difference found in mean FLACC score in both males and females among standard and pragmatic group. There was no significant difference found in mean MBPS score associated with any particular gender (male or female) in standard or pragmatic group.

\section{Recommendations}

i. The "standard of care" slow technique was significantly more painful and took longer to administer than the "pragmatic" rapid technique. Therefore, the pragmatic technique is suitable for routine use in vaccination clinic and significantly decreases vaccination related pain.

ii. It is quicker, therefore useful in large population undergoing vaccination.

iii.As it is technically simpler, it is easy to train a vaccinator with this technique.

iv. It is also cost effective compared with other methods of pain reduction such as pharmacological method.

v. Pragmatic method of vaccination has better parental vaccine compliance because of reduced pain and the administration of more injections at the same visit because of less overall injection time.

\section{References}

[1] Schechter NL, Berde CB, Yaster M. Pain in infants, children, and adolescents: an overview. In: Schechter NL, Berde CB, Yaster M, eds. Pain in Infants, Children, and Adolescents. Baltimore, MD: Williams \& Wilkins; 1993: 3-9. 
[2] Walco GA, Cassidy RC, Schechter NL. Pain, hurt, and harm: the ethics of pain control in infants and children. N Engl J Med. 1994; 331: 541-544.

[3] Jay S. Invasive medical procedure: psychological intervention and assessment. In: Routh D, ed. Handbook of pediatric psychology. New York: Guilford, 1998: 410-25.

[4] Jacobson RM, Swan A, Adegbenro A, Ludington SL, Wollan PC, Poland GA, Vaccine Research Group. Making vaccines more acceptable - methods to prevent and minimize pain and other common adverse events associated with vaccines. Vaccine. 2001 Mar 21; 19 (17-19): 2418-27.

[5] The Vaccine Administration Taskforce. UK Guidance on best practice in vaccine administration, London: Shire Hall communications, 2001.

[6] Choidini J. Best practice in vaccine administration. Nurs Stand 2001; 16: 35-8.

[7] Beyea S, Nicoll L. Administration of medications via the intramuscular route: an integrative review of the literature and research-based protocol for the procedure. Appl Nurs Res 1995; 8: 23-3.

[8] Rodger MA, King L. Drawing up and administering intra muscular injections:a review of the literature. J Adv Nurs 2000; 31: 574-82.

[9] Zelmen S. notes on techniques of intramuscular injection. Am J Med Sci1961; 241: 47-58.

[10] Chiodini J. Vaccine administration. Nurs Stand 2000; 14: 3842.

[11] Workman B. Safe injection technique. Nurs Stand 1999; 13: 47-53.

[12] Nicoll LH, Hesby A. IM injection: An integrative research review and guideline for evidence based practice. Appl Nurs Res 2002; 15: 149-162.

[13] National Research Council. Recognition and alleviation of pain in laboratory animals. National Academies Press; 2010 Jan 14.

[14] The Assessment and Management of Acute Pain in Infants, Children and Adolescents. PEDIATRICS Vol. 108 No. 3 September 2001 793-797.

[15] Schechter NL, Allen DA, Hanson K. Status of pediatric pain control: a comparison of hospital analgesic usage in children and adults. Pediatrics 1986; 77: 11-5.

[16] McGrath PA, Brigham MC. The assessment of pain in children and adolescents. In: Turk DC, Melzack R, eds. Handbook of Pain Assessment. New York, NY: Guilford Press; 1992: 295-314.

[17] Jay SM, Elliot CH. A stress inoculation program for parents whose children are undergoing painful medical procedures. J Consult Clin Psychol. 1990; 58: 799-804.

[18] Berry PH, Chapman CR, Covington EC, Dahl JL, Katz JA, Miaskowski C, McLean MJ. Pain: current understanding of assessment, management, and treatments. National Pharmaceutical Council and the Joint Commission for the Accreditation of Healthcare Organizations, VA, USA. 2001 Dec: b44.

[19] Crellin DJ, Harrison D, Santamaria N, Huque H, Babl FE. The
Psychometric Properties of the FLACC Scale Used to Assess Procedural Pain. J Pain. 2018 Mar 15.

[20] Merkel S, Voepel-Lewis T, Shayevitz JR, et al:The GLACC: A behavioural scale for scoring postoperative pain in young children. Pediatric nursing 1997; 23:293-797. Robieux I Kumar $\mathrm{R}$ et al. Assessing pain and analgesia with a lidocaine prilocaine emulsion in infants and toddlers during venipucture. J Pediatr. 1991; 118: 971-973.

[21] Taddio A Nulman I et al. A revised measure of acute pain in infants. J Pain.

[22] Symptom Manage. 1995; 10: 456-463.

[23] Wikipedia, the free encyclopedia. Immunization. Available at: https://en.wikipedia.org/wiki/Immunization. Accessed March $21,2018]$.

[24] Pain Reduction During Pediatric Immunizations: EvidenceBased Review and Recommendations Neil L. Schechter et al Pediatrics 2007; 119; e1184-e1198.

[25] Available at: http://www.iapcoi.com/pdf/chapter01 introduction. Accessed March 21, 2018.

[26] Available at: http://www.iapindia.org/page.php?id=129. Accessed December 5, 2017.

[27] Available at:http://www.who.int/immunization/policy/Immunization_rou tine table2 accessed on 10/05/2018. Accessed October 2, $201 \overline{7}$.

[28] Availableat:http://www.cdc.gov/vaccines/pubs/pinkbook/down loads/appendices/D/vacc a dmin accessed on 08/05/2018. Accessed March 16, $201 \overline{8}$.

[29] World Health Organization. Safety of injections in immunization programmes: WHO recommended policy. InLogistics for Health Information Series (WHO) 1994. World Health Organization.

[30] Hanson DJ. IM injection injuries and complications. Am J Nurs 1963; 63: 99-101.

[31] Diggle L, Deeks J. Effect of needle length on incidence of local reactions to routine immunization in infants aged 4 months. BMJ 2000; 321: 931-933.

[32] Available at: http://www.iapcoi.com/pdf/chapter08practicalaspects accessed on 10/05/2018. Accessed March 16, 2018.

[33] Availableat:http://www.dh.gov/prod_consum_dh/groups/dh_di gitalassests/@dh/@en/d ocuments/digitalasset/dh_121552 ${ }^{-}$p 26 accessed 10/05/2018. Accessed October 24, 2017.

[34] Bergeson PS, Singer SA, Kaplan AM. IM injections in children. Pediatrics 1982; 70: 944-948.

[35] Beyea SC, Nicoll LH. Administration of medications via IM route: An integrative review of literature and research based protocol for the procedure. Appl Nurs Res 1995; 8: 23-33.

[36] Groswasser J, Kahn A, Bouche B, Hanquinet S, Peri muter N, Hessel L. Needle length and injection technique for efficient IM vaccine delivery in infants and children evaluated through an ultrasonographic determination of subcutaneous and muscle layer thickness. Pediatrics 1997; 100: 400-403. 
[37] Nicoll LH. IM injection: updated information. SIGN September. 2002; 1-2.

[38] Clements CJ. Aspiration before injection. SIGN January; $2003 ; 1-2$.

[39] Mary Catlin. Aspiration before injection: Part 2. SIGN January 2003; 1-2.

[40] CDC. Vaccine Administration. In: General recommendations on Immunisation. Eds. William LA, Larry P, Benjamin S, Bruce W, John lskander, John Watson, Atlanta, USA. MMWR 2002; 51 (RR02): 11-14.

[41] Taddio A, Wong H, Welkovics B, Ilersich AL, Cole $\mathrm{M}$, Goldbach M, Ipp M. A randomized trial of the effect of vaccine injection speed on acute pain in infants. Vaccine. 2016 Sep 7; 34 (39): 4672-7.

[42] O'Brien L, Taddio A, Ipp M, et al. Topical 4\% amethocaine gel reduces the pain of subcutaneous measles-mumps-rubella immunization. Pediatrics 2004; 114: e720-4.

[43] Taddio A, Nulman I, Goldbach M, et al. Use of lidocaineprilocaine cream for immunization pain in infants. J Pediatr 1994; 124: 643-8.

[44] Ipp MM, Gold R, Greenberg $S$, et al. Acetaminophen prophylaxis of adverse reactions following immunization of infants with diphtheria-pertussis-tetanustoxoids-polio vaccine. Pediatr Infect Dis J 1987; 6: 721-5.
[45] Huang FY, Huang LM. Effect of local massage on immunization: DTP and DTPa. Acta Paediatr Taiwan 1999; 40: $166-70$.

[46] Girish GN, Ravi MD. Vaccination related pain: comparison of two injection techniques. The Indian Journal of Pediatrics. 2014 Dec 1; 81 (12): 1327-31.

[47] Ipp M, Taddio A, Sam J, Gladbach M, Parkin PC. Vaccinerelated pain: randomised controlled trial of two injection techniques. Archives of disease in childhood. 2007 Dec 1; 92 (12): 1105-8.

[48] Committee on Infectious Diseases. Active immunization: report of the Committee on Infectious Diseases, In: Pickering LK, ed. Red book. 27th ed. Elk Grove Village, IL: American Academy Paediatrics, 2006: 9-51.

[49] Ipp M, Sam J, Parkin P. Needle aspiration and intramuscular immunization. Arch Pediatr Adolesc Med 2006; 160: 451.

[50] Ipp M, Goldbach M, Greenberg S, et al. Effect of needle change and air bubble in syringe on minor adverse reactions associated with DPT-polio immunization in infants. Pediatr Infect Dis 1990; 9: 291-2.

[51] Sisson H. Aspirating during the intramuscular injection procedure; a systematic literature review. J Clin Nurs 2015 sep; 24 (17-18): 2368-75. 